\title{
INFLUENCE OF THE REUSE OF OSB AND MARINE PLYWOOD FORMWORKS ON SURFACE CONCRETE AESTHETICS
}

\author{
Luc COURARD, Cécile GOFFINET, Nathalie MIGEOTTE \\ University of Liege, ArGEnCo Department, GeMMe Building Materials, Belgium \\ Marie MARTIN \\ Belgian Construction Certification Association, Belgium \\ Julie PIERARD and Valérie POLET \\ Belgian Building Research Institute, Concrete Technology Laboratory, Belgium
}

\begin{abstract}
Concrete surface quality becomes more and more important because aesthetics requirements tend to spread over a wide variety of construction works. Even if it is difficult to clearly define what is beautiful or not, existing techniques maybe used to quantify aesthetic properties of concrete. As they mainly depend on formwork, the research project focuses on the reuse of two types of panels - plywood and OSB - and two types of release agents vegetal and mineral oils. Evolution of surface properties is measured through lightness and absorption. For plywood formworks, beyond 80 reuses, a modification of surface quality is noticed; this is only 50 for OSB panels. For both types of formworks, the release oil doesn't seem to have a major influence on formwork absorption. It is also observed that alkalis cause early degradation of the panels: release agents are not always efficient to avoid this phenomenon. Finally, if reuse doesn't have any influence on the absorption of the plywood formworks, it is not the case for OSB formworks.
\end{abstract}

Keywords concrete, aesthetics, formwork, colour, lightness, reuse, plywood, OSB, wear, alkali

\section{Introduction}

Since a few years, the requirements of architects and building owners with regard to the quality of the concrete surface become more stringent [1]. Aesthetics requirements are no longer limited to architectural work, but tend to spread over a wide variety of construction works, including on site concrete placing structures (Fig.1).

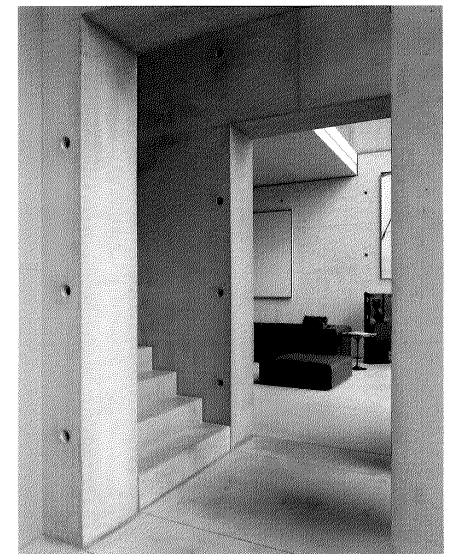

Fig.1a Interior of a private house/ Arch. A. Verdickt (Ph. K. Zwarts) [2]

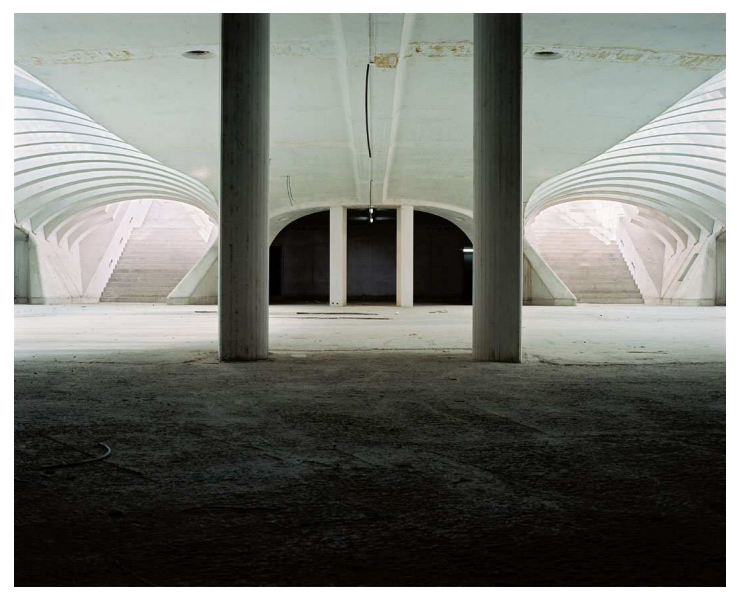

Fig.1b Liège - Guillemins station/SNCB/Euro Liège TGV/Arch. S. Calatrava (Ph. A. Janssens) 
Aesthetic quality of concrete surface is usually characterized by its color and its texture $[3,4$, 5]. Color is influenced and conditioned by concrete skin physical characteristics [6, 7] (Fig.2); it mainly depends on the chemical composition of cement and aggregates, as well as the porosity of this concrete skin (e.f. the thin layer of cement paste just beneath the surface). Casting conditions also have a significant influence [8].

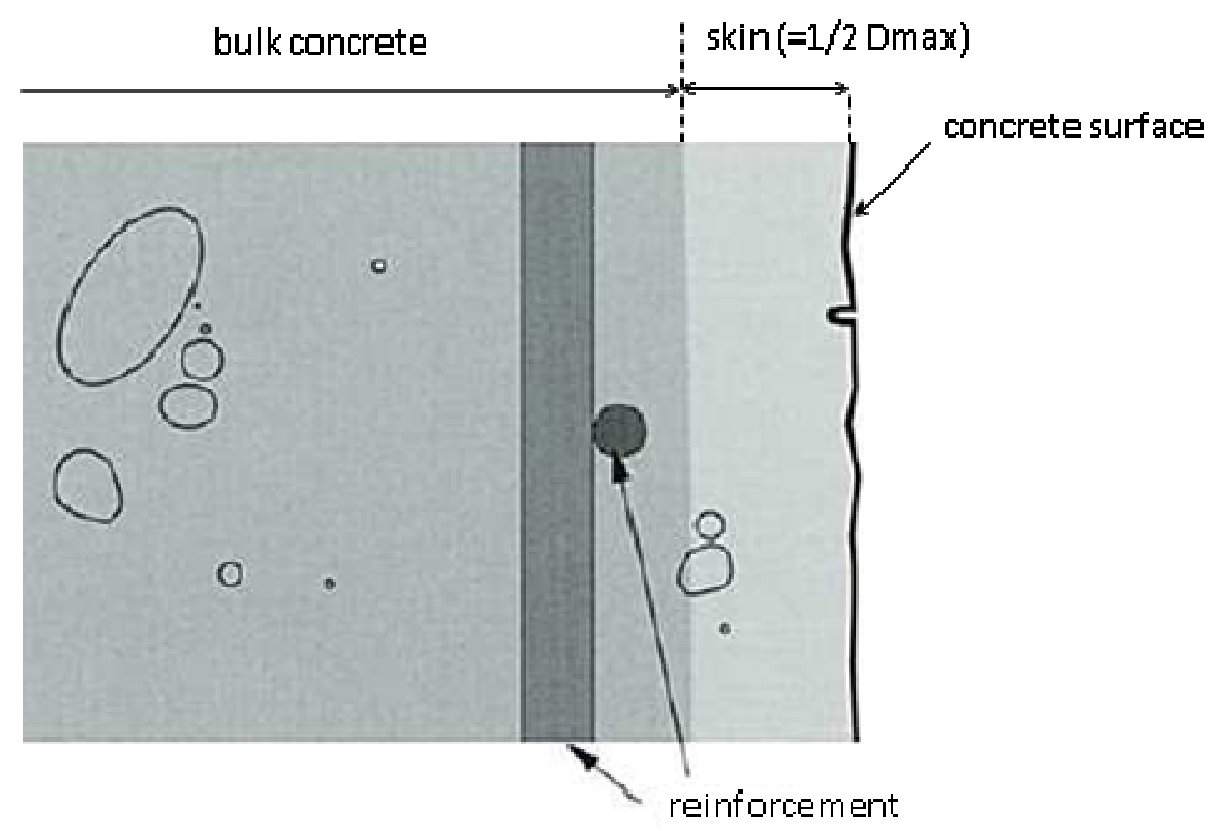

Fig.2 Concrete skin characteristics

The development of tools to characterize the color of concrete surfaces and the study of the effects of various parameters influencing the color (Fig.3) only begin to emerge [1,9]. Some researchers firstly propose a scientific approach to investigate the color as a measurable aesthetic property of concrete $[10,11]$. But the aesthetic quality of concrete surfaces is also related to their texture (in terms of roughness and lightness), which depends on the chemical and physical properties of the concrete skin at a microscopic level [7, 12]. But other parameters have to be mentioned, including type and quality of materials, W/C, environmental conditions of working, casting technology, curing ... and, finally, formwork material $[13,14]$.

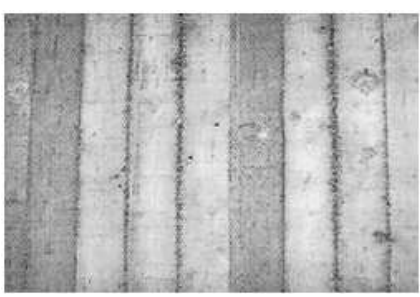

(a)

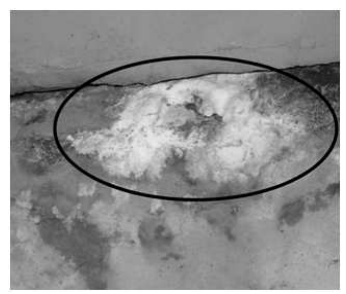

(b)

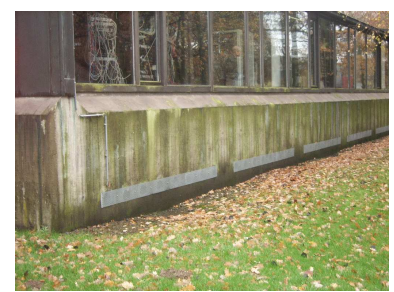

(c)

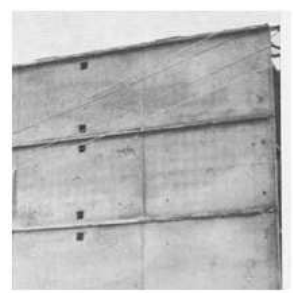

(d)

Fig. 3 Color defects of concrete surface (a) formwork differential absorption, (b) exudations (c) dirts, (d) steel bars spectrum

The formwork is the principal material which gives the form, the color and the texture of the concrete surface: it's the negative view of the concrete. Moreover, it represents 25 to $75 \%$ of the final cost of concrete placing $[1,15]$. The formwork is therefore a very important element 
in the concrete industry and must not be neglected [16, 17]. In order to have a relatively homogenous surface of concrete, the formwork surface must be clean, free of defects and as smooth as the surface to be obtained [18]. But one of its specific properties must be the homogeneity of its absorption capacity (Fig. 3a) [4, 5].

Wooden slats are very popular as formworks elements in order to give some specific texture to the concrete surface (Fig. 3.a). These slats may be sawed, assembled and reused. Raw wood, marine plywood or OSB panels may also be used, regarding the dimensions of the structural element, the surface flatness and also the texture of the concrete [19] that has to be obtained. Cement based material naturally interact with formwork material [20]: it is usually assumed that, with reuse, the pores of the wood are gradually filled up with the laitance of the mix. This tends to induce a brightening of the concrete surface [15]. The maximum number of reuses of a formwork depends on the formwork material and is usually between 30 and 60 for plywood boards and around 20 for OSB boards. Unfortunately, these assumptions have never been experimentally verified and the long term behavior of the formworks, with regard to concrete final surface, has never been studied.

This research project tends to quantify formwork and concrete colour surface characteristics evolution with rate of reuse in order to help architect and practitioner to select most appropriated formwork type with regard to the number of presumed reuses.

\section{Methods and materials}

\subsection{Parameters of the experiment}

Four sets of two types of wooden panels are used in this experiment: two sets of marine plywood panels (Fig. 4a) and two sets of OSB panels (Fig.4b). Each set of boards is used with 2 different release agents: a mineral oil (Sika Decoffre) and a vegetable oil (Sika TR-22).

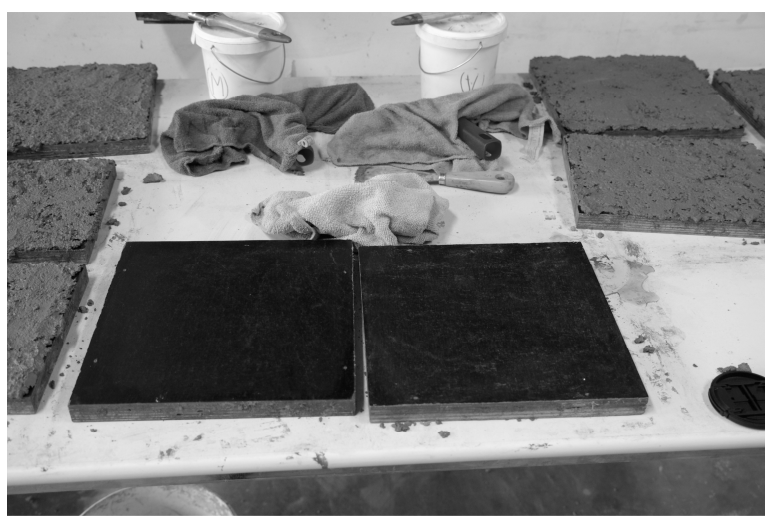

(a) marine plywood panel

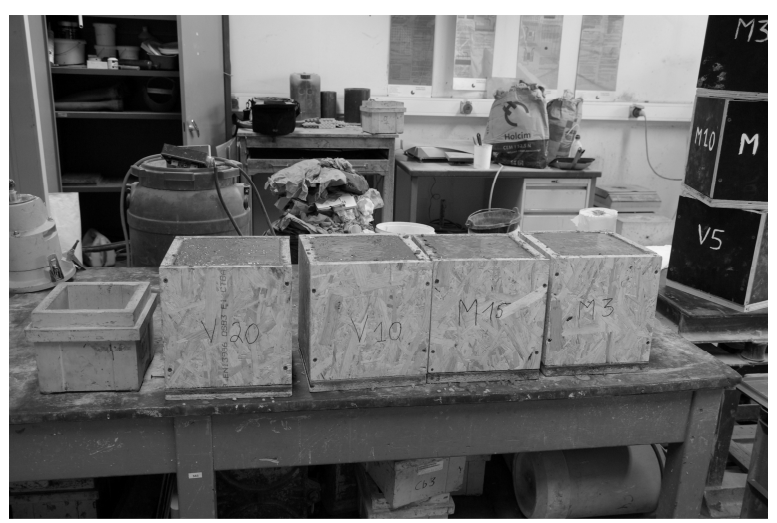

(b) OSB panel

Fig. 4 Types of wooden panels

\subsection{Reuse of formworks: ageing cycle}

The formwork panels are assembled as cubes of 300x300x300mm (Fig. 4b); 12 plywood cubes and 4 OSB cubes, respectively, were dismantled in order to get 5 formworks boards each. As the objective of the research project is to evaluate the influence of the reuse of formwork on the color of concrete, each board (Fig. 5) is then reused several times going from 2 to 51 for the OSB boards and from 1 to 118 for the plywood boards: each time corresponds to one wear cycle. 


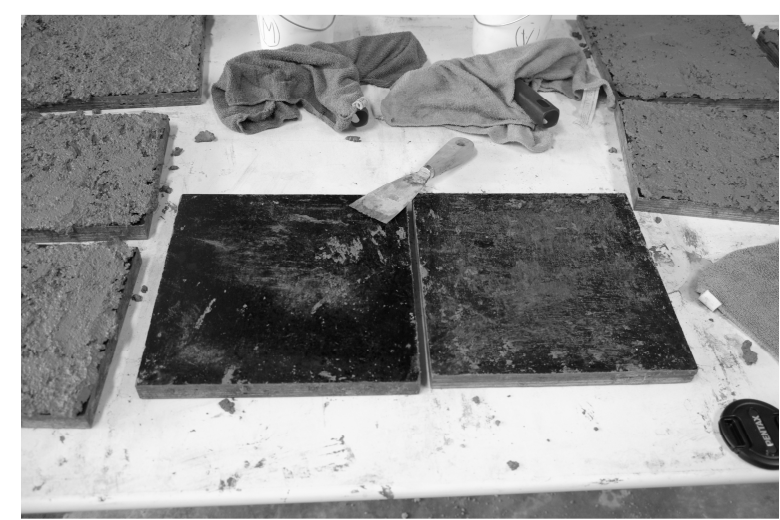

(a) removing of the mortar

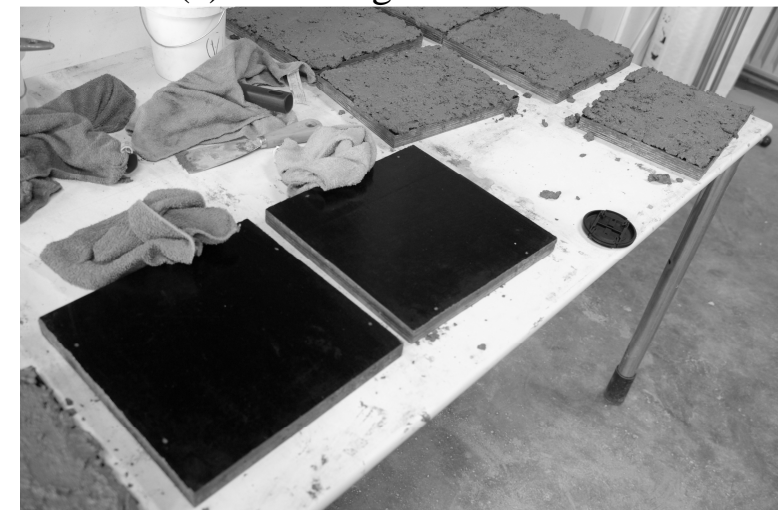

(b) application of oil

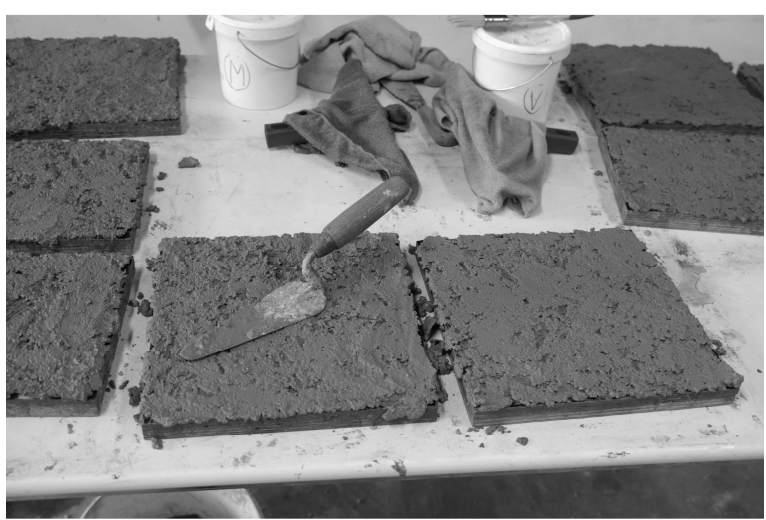

(c) application of the mortar

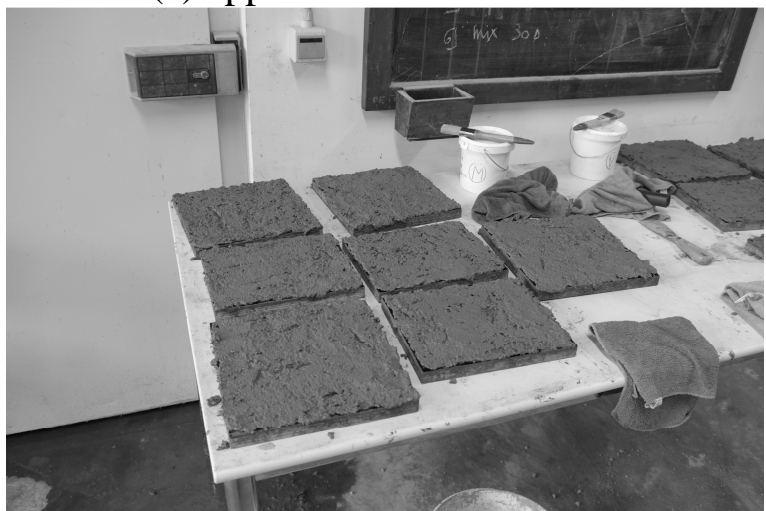

(d) storage of the samples

Fig. 5 Procedure of ageing of wooden formworks

In order to reproduce with accuracy mechanical and chemical wears occurring when placing the concrete, a layer of mortar (Table 1) is laid on each panel (Fig. 5c) with a trowel.

Table 1 Mortar mix design

\begin{tabular}{ll}
\hline Material & Quantity [kg/kg mortar] \\
\hline CEM I 52.5 N & 0.284 \\
Rounded Sand 0/2 & 0.574 \\
Water & 0.142 \\
W/C & 0.5 \\
Mortar & 1 \\
\hline
\end{tabular}

Each wear cycle is finally consisting into the following operations:

1. the hardened mortar from the previous cycle is removed with a scraper (Fig.5a);

2. the panels are washed with wet washcloths and then dried;

3. the release oil is brushed on the panels and rests for 30 minutes (Fig.5b);

4. the oil excess is removed;

5. a layer of mortar is troweled on each panel (Fig.5c);

6. the mortar hardens on the panel for approximately 2 hours (Fig.5d).

One cycle corresponds to one use. These steps were therefore repeated up to 118 times for plywood and 51 times for OSB panels, respectively, in order to get the expected level of reuse. Intermediate levels of ageing are considered to measure the evolution of surface characteristics of concrete and formworks. 
Mortar is removed after 2 hours because we consider that its potential effect on formwork (through water absorption or alkalinity) is no more efficient [21].

\subsection{Concrete samples preparation}

Once the panels have reached their reuse level minus one cycle, the cubes are reassembled and the watertightness is assured by silicone joints. After 24 hours, release oil is laid and, 30 minutes later, the concrete is cast. In order to assure the homogeneity of the mix for all the cubes, concrete (Table 2) is coming from the same batch for all the samples.

Table 2 Concrete characteristics (according to EN 206-1)

\begin{tabular}{ll}
\hline Compressive class & $\mathrm{C} 25 / 30$ \\
Concrete type / Chloride class & Reinforced concrete / $(\mathrm{Cl} 0,40 \%)$ \\
Environmental class & EE2 \\
Consistency class & $\mathrm{S} 4$ \\
$\mathrm{D}_{\max }$ & $8 \mathrm{~mm}$ limestone aggregates \\
Cement & $\mathrm{CEM} \mathrm{III/A} \mathrm{42,5} \mathrm{N} \mathrm{LA}$ \\
\hline
\end{tabular}

Concrete is cast with high level of compaction (vibrating table) and the placing procedure is identical for all of them. After casting, the test specimens are covered with wet burlap and a polyethylene sheet for 48 hours. They are then stripped and stored in the laboratory $\left(21^{\circ} \mathrm{C}\right.$ and $50-70 \%$ R.H.). When stripping the cubes, each face is carefully identified since it corresponds to a different level of wear.

\subsection{Color and lightness measurement procedure}

When light comes into contact with concrete surface, major part of the light is reflected (diffused reflection). The reaction of light in contact with a surface is composed of two phenomenons: the absorption of a part of the light spectrum and the diffusion of light into the material. Absorption gives the chromaticity to the material and diffusion gives the darkness to materials $[1,11]$. The colorimetric coordinates are measured with a colorimeter in the $\mathrm{L}^{*} \mathrm{a}^{*} \mathrm{~b}^{*}$ color space. Concrete is lighted with Standard light and the reflected light from concrete is analyzed by the colorimeter for giving $\mathrm{L}^{*}, \mathrm{a}^{*} \mathrm{~b}^{*}$ value of concrete.

- $\quad L^{*}$ Value corresponds to lightness of concrete that means more or less dark.

- $\quad a^{*}$ Value corresponds to value in axis green / red

- $\quad b^{*}$ Value in axis Yellow / blue.

Normal color of concrete is grey: $a^{*}$ and $b^{*}$ values are generally low for concrete and don't change a lot. The most important value for concrete is $\mathrm{L}^{*}: \mathrm{L}^{*}=100$ is white $\mathrm{L}^{*}=0$ is black. Normal grey concrete are generally around 60, but this value can change a lot with the darkness of concrete (55 for dark concrete and 75 for light concrete) [1].

For all the faces of the cubes, as well as for all the panels, the colorimetric coordinates are measured in 6 different points, identical for all the surfaces, in order to evaluate a potential variation on the height or the width of the surface (Fig.6).

Color may change with time: in order to detect possible evolution of the color of concrete, measurements are carried out in four campaigns corresponding to different time intervals of 7, 42, 49 and 75 days after stripping, respectively. 


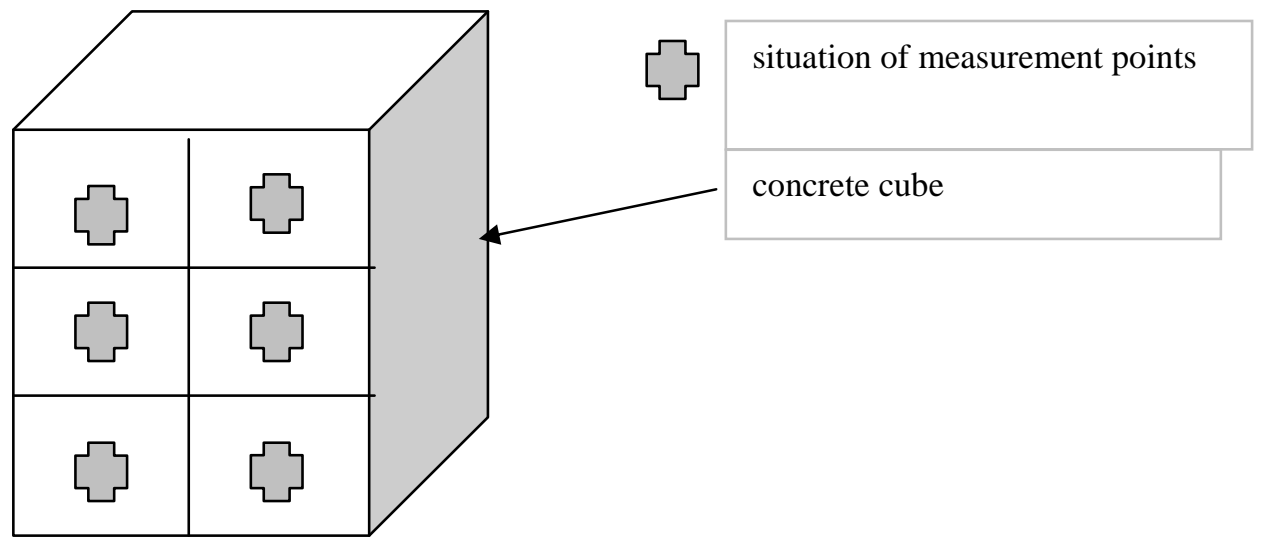

Fig. 6 Color and lightness measurement points on concrete and formwork surface

\subsection{Absorption capacity evaluation}

After color evaluation, the panels are then sawed in two parts and water absorption is measured. Test is performed according to NBN B15-215 standard [22] and the next specific procedure:

1. preparation of the test specimen : all faces are covered with epoxy resin, except one;

2. dry weighing $\left(\mathrm{W}_{\mathrm{d}}\right)$;

3. water immersion for $4 \mathrm{~h} 40$;

4. wet weighing $\left(\mathrm{W}_{\mathrm{w}}\right)$.

The water absorption of the panels is evaluated with Eq. 1:

$A=\frac{W_{w}-W_{d}}{W_{d}}$

where $\mathrm{A}$ is the absorption of the panel measured in $\%, \mathrm{~W}_{\mathrm{w}}$ is the wet weight of the test specimen measured after water immersion and $\mathrm{W}_{\mathrm{d}}$ is the dry weight of the test specimen measured before water immersion.

\section{Evolution of panel's wear}

\subsection{Evolution of the lightness with time}

Figure 7 shows the evolution of the lightness with the number of reuse of formworks for plywood formworks used with mineral oil and for the four different terms of measurement. Coefficient $\mathrm{L}^{*}$ gives an evaluation of the lightness of the material [4]. 


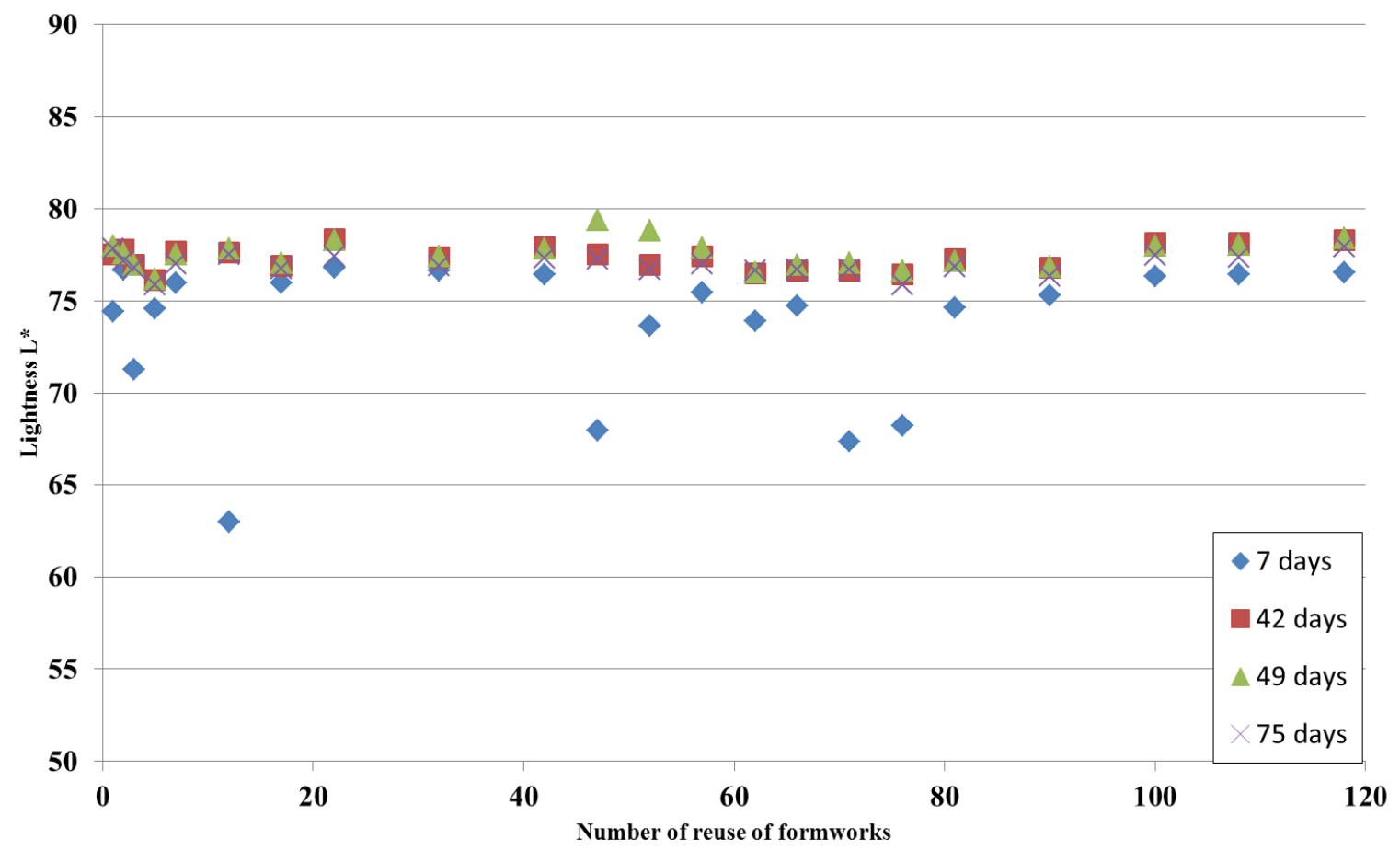

Fig. 7 Evolution of the lightness versus the number of reuse of formworks for plywood formworks plus mineral oil, for the four different terms of measurement, respectively

The results show that the moment when the measurements are carried out has an influence on the lightness of the panels: indeed, the variability of the lightness decreases with time. The variance of the lightness for the 4 interval times (Table 3) considerably decreases between the measurements carried out 7 days after stripping and the measurements performed later at 42 , 49 and 75 days after stripping, respectively: the maximum difference in lightness for OSB and plywood's at 45 days is 4 while it is around 15 at 7days. For these three last campaigns, the variance remains quite low.

Table 3 Lightness variance for the 4 campaigns of measurement

\begin{tabular}{cc}
\hline Measurement term & Variance \\
\hline 7 days & 14.36 \\
42 days & 0.42 \\
49 days & 0.60 \\
75 days & 0.29 \\
\hline
\end{tabular}

The second observation we can make from Fig. 7 is that concrete brightens up with time: the results at 7 days are indeed always smaller than the results obtained later. This observation may be explained by the variation of the moisture of the concrete: the moister the concrete is, the darker it is $[1,12]$. When the concrete is stripped, it is very moist since cement is not completely hydrated and formwork keeps the superficial moisture from evaporating. As time goes by, concrete becomes more and more hydrated and the water excess evaporates, which leads to the brightening of the material.

Considering these results, only measurements carried out at 75 days have been considered in the next investigations. 


\subsection{Evolution of the absorption of formworks}

The second investigation concerns the evaluation of the evolution of the absorption of plywood (Fig. 8) and OSB (Fig. 9) formworks with the number of reuse and the release agents.

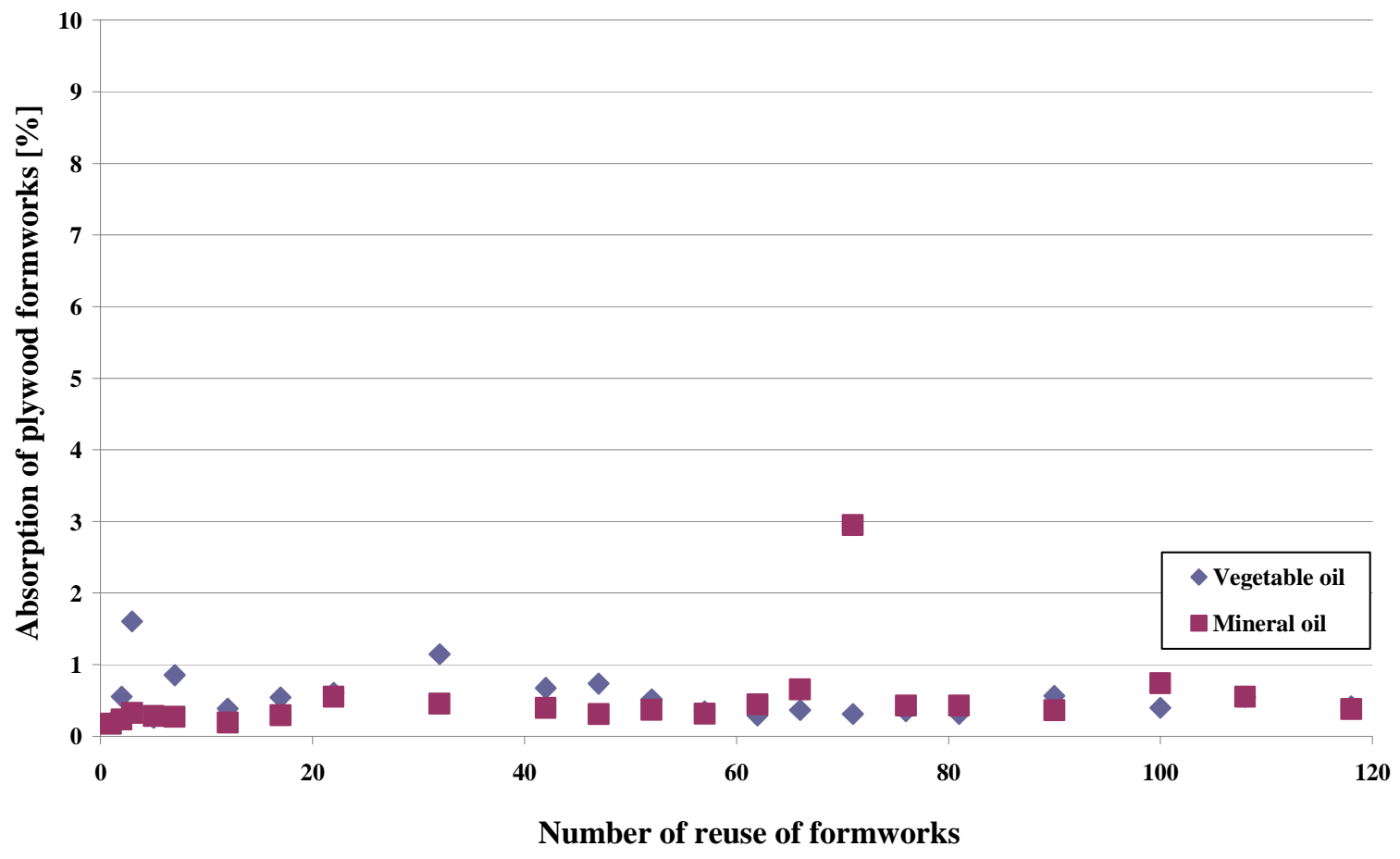

Fig. 8 Evolution of the absorption of plywood formworks with the number of reuse for the two release agents 


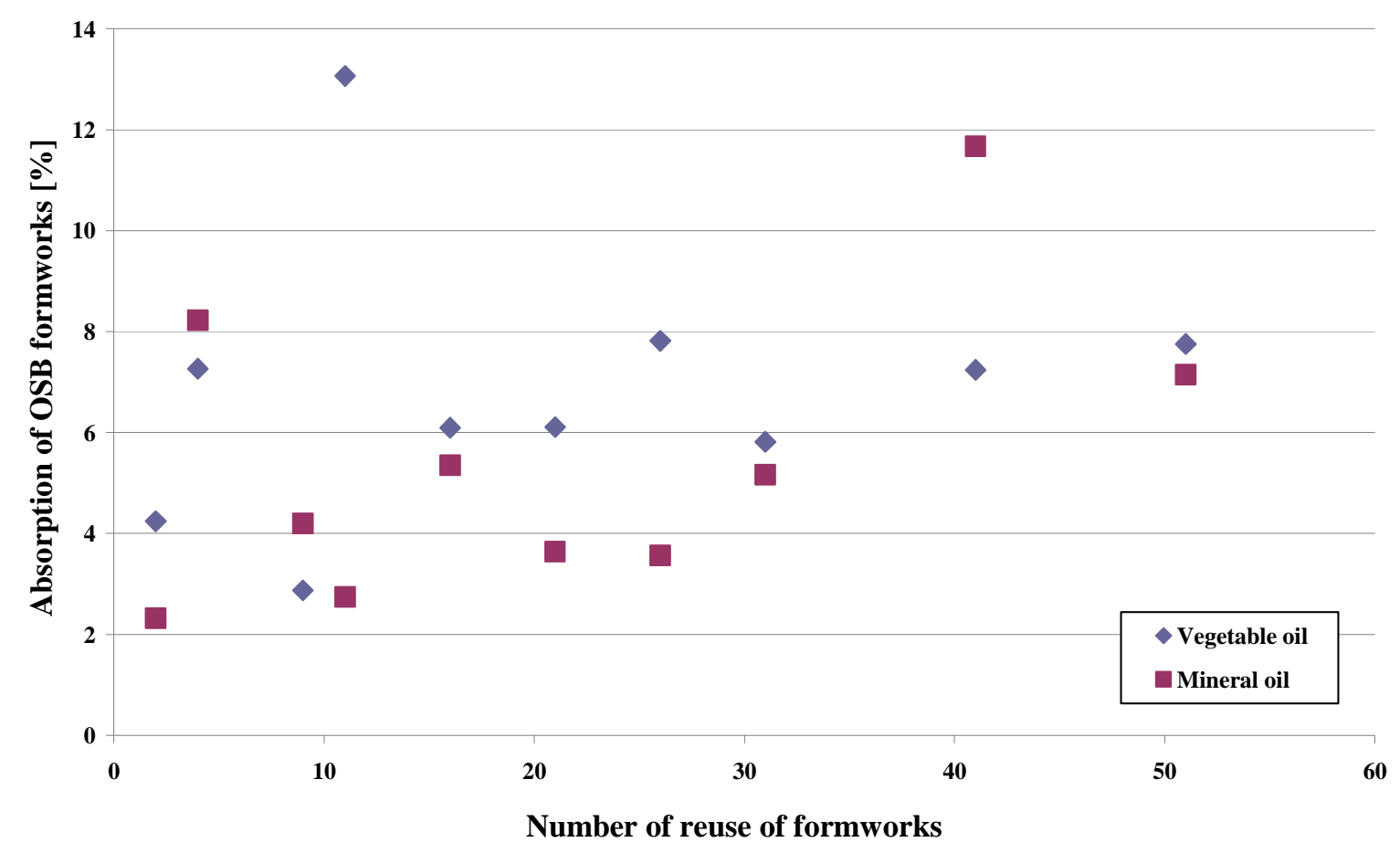

Fig. 9 Evolution of the absorption of OSB formworks with the number of reuse for the two release agents

For both types of formworks, the release oil doesn't seem to have an influence on absorption. On the other hand, two different behaviors may be considered for the evolution of the absorption with regards to the type of the formwork.

Firstly, it is clear that the reuse doesn't have an influence on the absorption of the plywood formworks: it stays very low, between 0 and $1 \%$ for all of time intervals, up to 120 reuses. However, concerning the OSB formworks, the absorption seems to increase with the reuse, which is in opposite with previous observations in the literature: Lallemant [11] observed indeed that the absorption of the formwork is supposed to decrease with the reuse, since the laitance of the concrete gradually fills up the pores of the wood [5]. The difference between what we could expect and what we observed probably comes from the way in which we used the formworks: each time we started a new cycle, the layer of mortar from the previous cycle is not completely dried when removed and a scraper is used, which probably damaged the board and eventually uncovered fibers of wood. This can be considered however as a common way of working on job site and the main risk of formwork surface degradation.

\subsection{Evolution of the lightness of the concrete}

Evolution of the formwork has an influence on the quality of concrete surface. But the evolution of the concrete characteristics has been also followed for the two types of formwork materials and release oils.

Evolution of the lightness can be subdivided into three parts (Fig. 10). For the formworks used with mineral oil, a first zone - from 1 to 17 reuses - is characterized by a quite high variability of the lightness ranges, i.e. between 75.88 and 77.83 . This variability is probably due to a certain "setting" of the properties of the formwork material, i.e. maritime plywood: since we used a different panel for each reuse level, the lightness of the concrete corresponding to the early reuses strongly depends on the initial properties of the formworks 
which can be quite random. As the reuse cycles go by, wear will settle these properties to the same level and the results will be less variable.

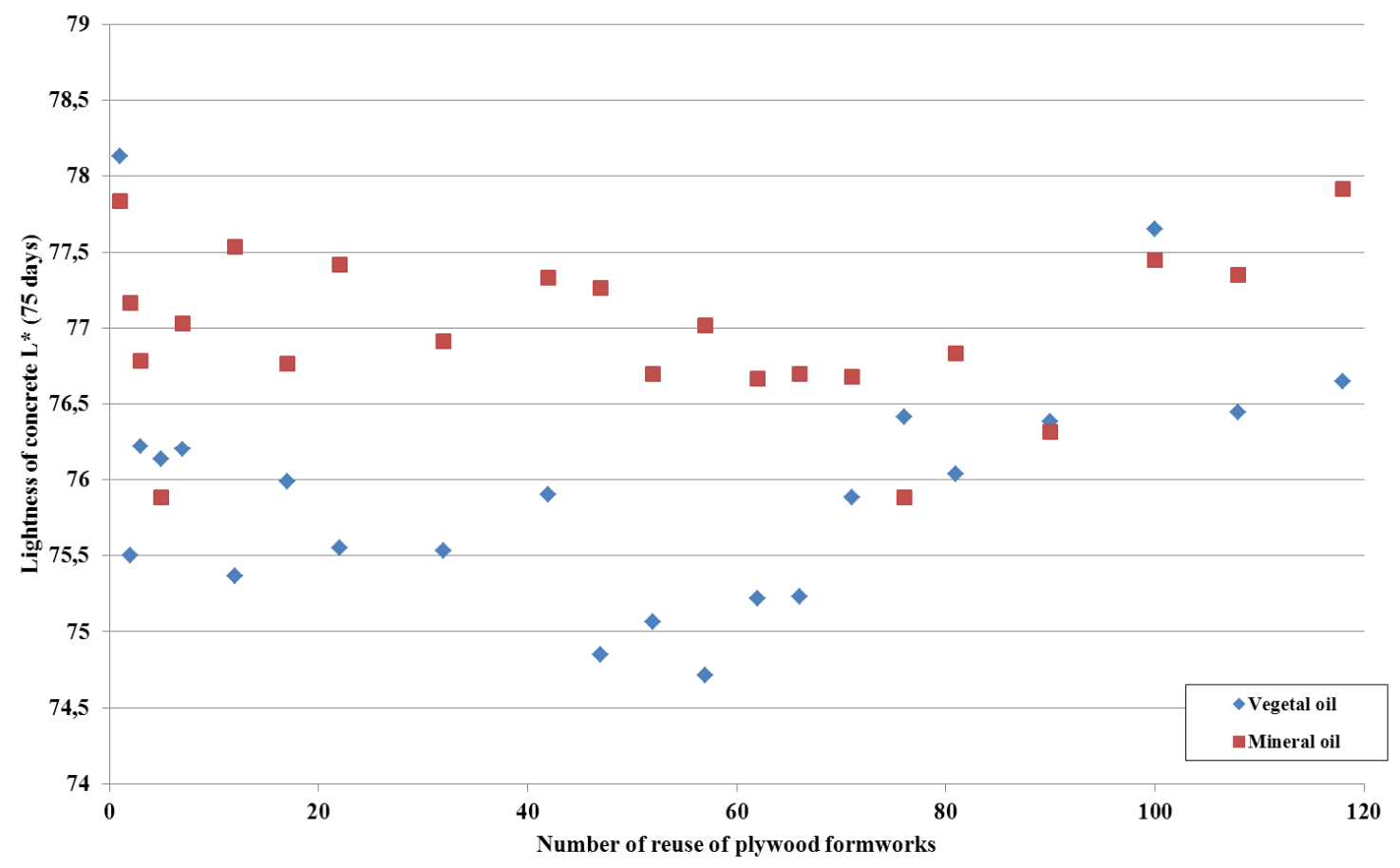

Fig. 10 Evolution of the lightness of the concrete with the number of reuse of the plywood formworks

The second is a stable zone in which lightness remains relatively constant. This stage corresponds to an optimal interval of reuse (from 22 to 71 ). The end of the stage is characterized by a clear break in the lightness evolution curve: this break corresponds to the appearance of the wear due to the reuse cycles.

The third and last zone starts at about 80 reuses and corresponds to the effect of the wear of the formworks: the material is damaged and the lightness of the concrete is affected. The consequent deterioration of the formworks induces an increase of the concrete lightness.

The subdivision of the evolution of the lightness observed with mineral oil can be observed with vegetable oil as well: a first part, from 1 to 7 reuses, is characterized by a high variability and a stable stage follows between 12 and 42 reuses. Finally, panels' wearing induces quicklier evolution after 50 reuses.

The main difference between the two release oils is the moment when the break due to the wear takes place: in the case of the vegetable oil, the break occurs at about 50 reuses while it goes up to 80 for mineral oil: the quality and the type of release oil has a real impact on the evolution of the lightness.

It is evident that a good quality release oil better protects the surface of the formwork from the wear and the ageing which makes longer the optimal interval of reuse. 


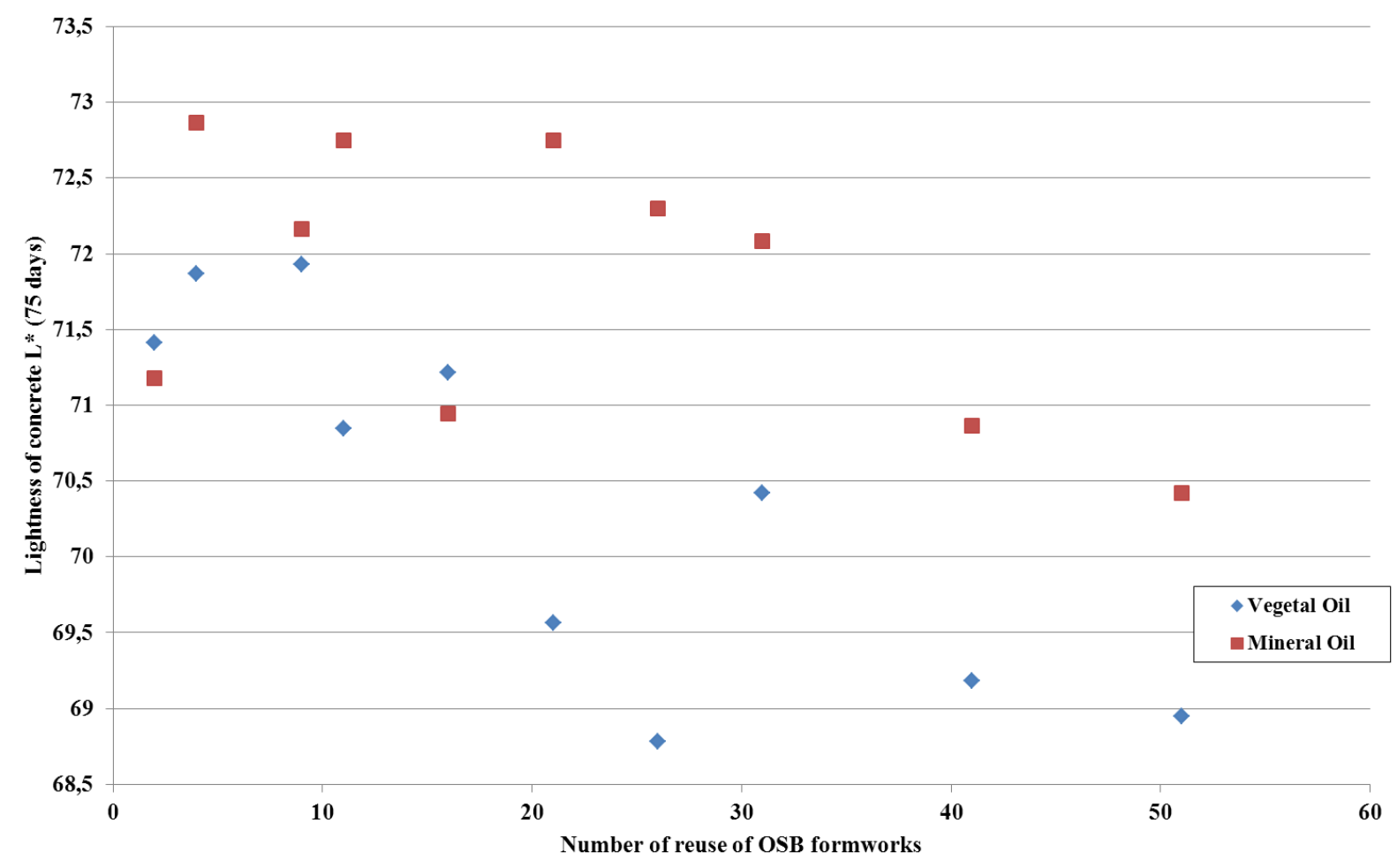

Fig. 11 Evolution of the lightness of the concrete with the number of reuse of the OSB formworks

This difference between the two types of oils was already observed during experimentation: after a dozen of cycles only, we already observe that the formworks prepared with vegetable oil seemed more affected than the other ones as they appear greyer than really black (Fig.12). Moreover, vegetable oil is less viscous than the mineral one and seems to quickly disappear from the surface by absorption or evaporation: the aspect of the formwork is more "greasy" or "covered" with mineral oil.

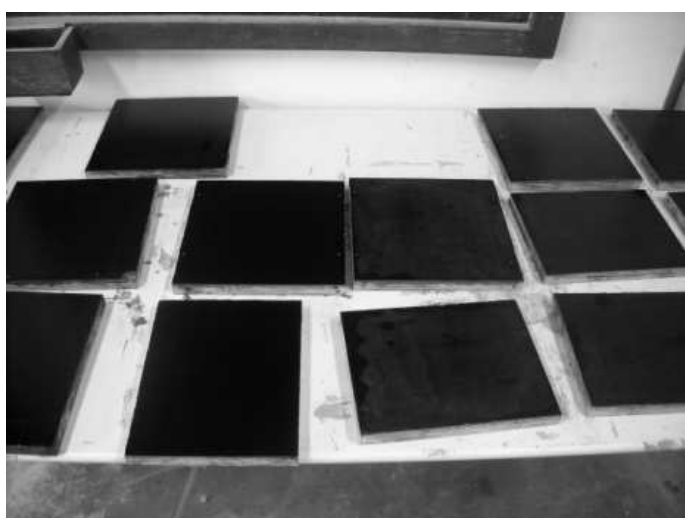

Fig. 12 Evolution of the formwork aspect after a dozen of reuse (with mineral oil on the left and vegetable oil on the right) 
When OSB formwork is used (Fig. 11), the evolution of the lightness can be divided into two parts. As previously, for mineral and vegetable oils, a first zone from 1 to 15 reuses may be defined and characterized by high lightness variability. This variability is probably again due to a certain setting of the properties of the OSB formwork. In a second zone, from 15 to 60 reuses, the lightness of concrete decreases while the number of reuses increases.

\subsection{Relationship between lightness and absorption}

The lightness of the concrete strongly depends on the absorption of the formwork [1, 5, 12]. Figure 13 presents the evolution of the lightness of the concrete with the absorption of the formwork, irrespectively to the type of formwork or release oil. In order to point out a trend corresponding to the reality, we decided not to take into account lightness measurement corresponding to the first cycles, which are 1 to 17 for the plywood formworks and 1 to 11 for the OSB.

The plotting of measurements clearly shows an evolution of lightness with absorption (Fig. 13). This trend correlation coefficient $\left(\mathrm{R}^{2}=0.871\right)$ probably corresponds to a darker surface induced by a decrease of $\mathrm{W} / \mathrm{C}$ ratio: the less absorptive the formwork, the brighter the concrete and, inversely, the more absorptive the formwork is, the darker the concrete is. These results clearly seem to confirm previous observations $[1,11,12,15]$.

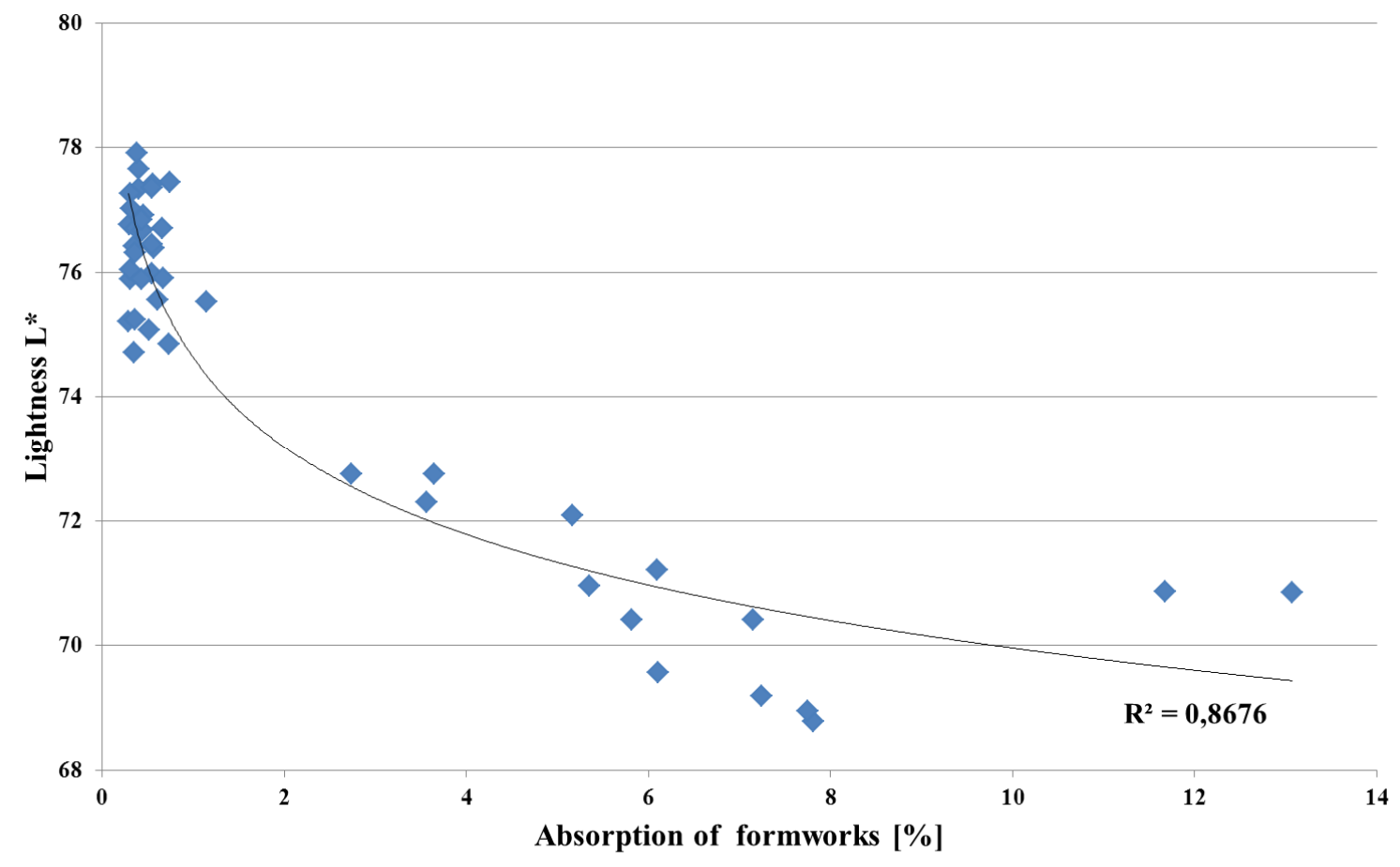

Fig.13 Evolution of the lightness of the concrete with the absorption of the formwork 


\section{Test results after chemical ageing}

\subsection{Context}

In the previous chapters, we tried to simulate wearing induced by repeated application of a layer of mortar on formwork panels. The repetition of these cycles may deteriorate the formwork in two ways: firstly, a mechanical action due to sand grains in the mortar application and the use of a scraper when cleaning the plate and, secondly, a chemical aggression from interstitial solution of cement based material.

This investigation therefore aims to differentiate the effect of these two types of aggression: effects of alkali and chemical attack is hereafter specifically analysed.

\subsection{Testing conditions}

The alkali attack is simulated by immerging the panels into chemical solution similar to the interstitial solution of concrete with a $\mathrm{W} / \mathrm{C}=0.45$ (Table 4). In order to accelerate the degradation process, higher concentration solution ( 5 times) is also used.

Table 4 Alkali concentration into cement based interstitial solution

\begin{tabular}{lcc}
\hline & Normal concentration (mol/l) & Concentrated solution (mol/l) \\
\hline $\mathrm{OH}^{-}$ & 0.760 & 4,20 \\
$\mathrm{Na}^{+}$ & 0.244 & 1,22 \\
$\mathrm{~K}^{+}$ & 0.596 & 2,98 \\
\hline
\end{tabular}

Several parameters are studied: solution type, presence and type of release agent. Four different testing conditions are analysed (Table 5): one with water and OSB and plywood samples without release agent and three others with alkaline solution.

Table 5 Testing conditions

\begin{tabular}{lcccc}
\hline & Condition 1 & Condition 2 & Condition 3 & Condition 4 \\
\hline $\begin{array}{l}\text { Solution } \\
\text { Release agent }\end{array}$ & Tap water & Alkaline solution & Alkaline solution & Alkaline solution \\
$\begin{array}{l}\text { Plywood } \\
\text { formwork }\end{array}$ & nAKE 1 & BAKE 2 & Vegetable oil & Mineral oil \\
OSB formwork & OSB 1 & OSB 2 & OSB 3 & BAKE 5 \\
\hline
\end{tabular}

The panels are immerged into solutions for a maximum duration of 345 hours. Color and lightness (Fig. 14) are measured before and after different time intervals. 


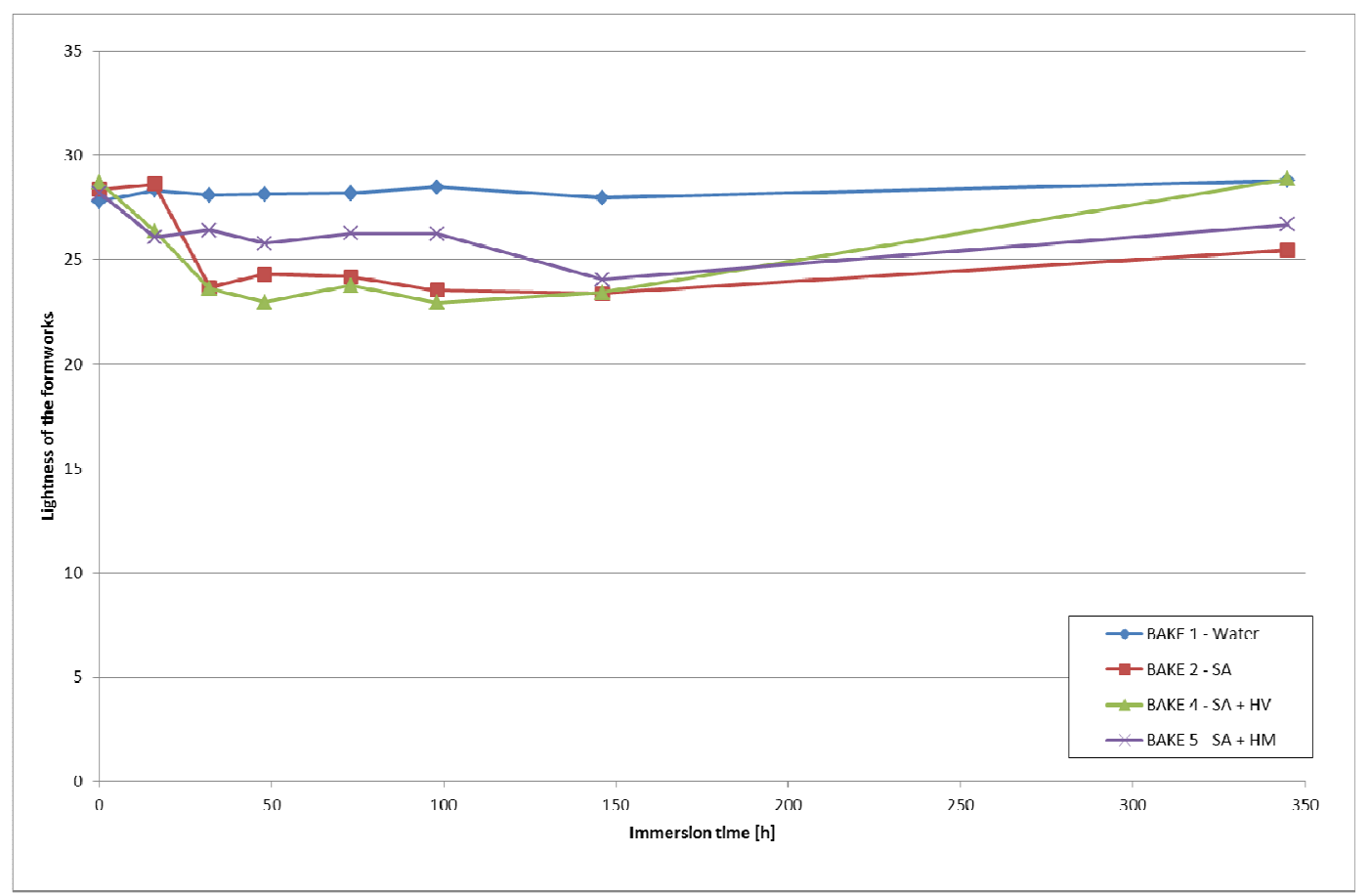

Fig. 14 Evolution of the lightness of the plywood formworks vs immersion time and solution

Two different behaviours can be observed, depending on whether the form has been immerged into water or alkaline solution. Water does not seem to influence the evolution of plywood formworks' lightness (BAKE 1). For formworks immerged into alkaline solution, a decrease of lightness is rapidly observed and followed by a stabilization phase. The loss of lightness, due to alkalis aggression, begins with the first immersion and takes about 32 hours; after that, lightness remains constant. While similar behaviour is observed for the formworks without (BAKE 2) and with vegetable oil (BAKE 4), mineral oil seems to induce a better protection and a reduction of loss of lightness (BAKE 5): after 150 hours immersion, lightness of the formwork remains higher than the two others. However, after this period, the protection effect disappears and behaviour becomes similar for all samples immerged into alkaline solution. 


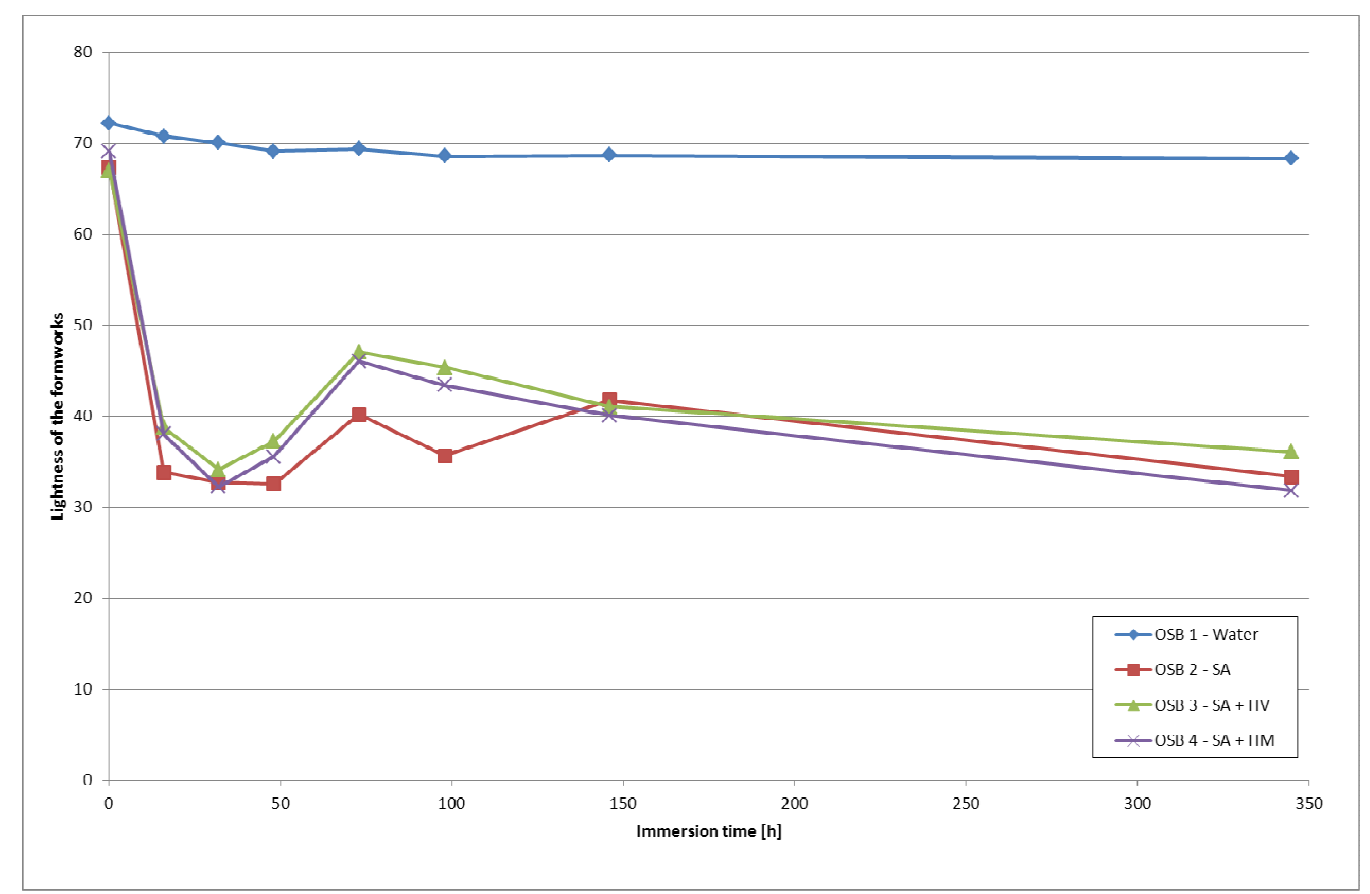

Fig. 15 Evolution of the lightness of the OSB formworks vs immersion time and solution

OSB forms present quite different behaviours than plywood (Fig. 15). Similarly to previous one, water has no effect on the surface aesthetic properties of the formwork. However, when immerged into alkaline solution, degradation process is more destructive and lightness's decrease is higher than with plywood. Once again, loss of properties mainly early happens (between 0 and 32 hours); a stabilization period is observed afterwards. On the contrary of what we observed with plywood formworks, oil type doesn't influence the loss of lightness. Moreover, no difference is observed with or without release agent.

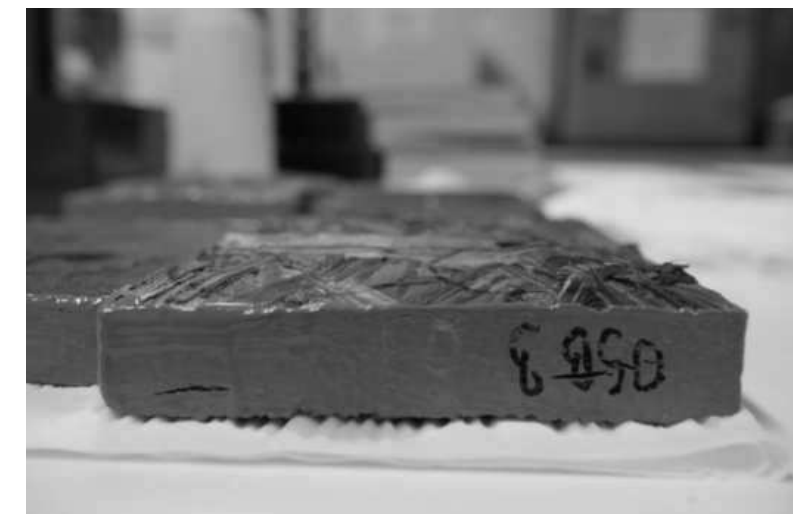

Fig.16 Aspect of OSB formworks after 72h immersion into alkaline solution

The deterioration is visually observed during testing process (Fig. 16): the samples dramatically swell after the first immersion period (16h) and doesn't change afterwards.

Bakelite organic resins may loose their rigidity and strength when they are in contact with high alkaline media. Combined with mechanical effect of mortar and trowels, it may induce a 
loss of smoothness of the plywood panel: this explains a modification of surface properties of formwork and concrete.

\section{Conclusions}

The reuse of OSB and marine plywood formworks has an influence on the color and, specifically, the lightness of the concrete. We can draw the following conclusions from the present results:

- plywood formworks surfaces change with the number of reuses. This evolution maybe measured through lightness coefficient $\mathrm{L}^{*}$. Three different phases have been pointed out: a first highly variable zone, a stable stage and a zone where lightness largely increases. The optimal interval of reuse for the plywood formworks used with mineral oils is between 20 and 80 . More than 80 reuses would induce a modification of surface quality;

- the type of release oil has an important impact since the quality of the oil determines the length of the interval in which no variation is observed. The use of vegetal oil induces in this case a lower reuse ratio of formwork (max. 50). Therefore, applying a bad quality release agent will have a bad influence on the color of the facings or lead to important economical and ecological consequences;

- for both types of formworks, the release oil doesn't seem to have an influence on formwork absorption. It is clear that the reuse doesn't have any influence on the absorption of the plywood formworks: it remains very low (between 0 and $1 \%$ ) up to 120 reuses. However, OSB formworks absorption largely increases with reuse;

- OSB formworks are more sensitive to reuse. From 15 reuses, the lightness of concrete decreases with the number of reuses: OSB becomes more and more absorbent and concrete facing becomes darker;

- water does not influence the properties of the formwork and the concrete surface. However, alkalis cause early degradation of the formwork; oil release agent may not be sufficient even if mineral oil seemed to be more effective;

- alkalinity is an effective factor of formwork degradation and release oil doesn't seem to have efficient protection effect.

Finally, there is a clear correlation between the lightness of the concrete and the absorption capacity of the formwork. As expected, we observed a decreasing of the lightness with the increasing of the absorption: this trend is very important since it has never been experimentally verified before this study. It shows that, as soon as the absorption coefficient is greater than 2 or $4 \%$, the lightness of the concrete surface dramatically decreases. With regard to the requirements of the architect, the formwork should be removed and replaced by a new one.

\section{Acknowledgements}

The authors wish to express their gratitude and sincere appreciation to the Regional Government of Wallonia (Belgium) and the Belgian Building Research Institute, for financing this research through First Post Doctoral Project BETEX+.

Special thanks are addressed to M. M. Deravet from Institut de Formation Sectoriel du Bâtiment (IFSB, GD of Luxembourg) who provided formworks. 


\section{References}

1. Lemaire G (2003) Contribution to the quality control and assessment of concrete surfaces. PhD Thesis, Université Paul Sabatier, Toulouse : 209p (in French).

2. Verdickt A (2009) Between walls: houses in faced self compacted concretes. Revue Febelcem (ed. A. Jasienski) : 26p (in French).

3. Pleau R, Henné J, Boulet D, Blais D and St-Pierre M (1999) Aesthetic Properties of Architectonic High- Performance Self-Levelling Concretes. Proceedings of the Creating with Concrete International Conference, Radical Design and Concrete Practices, Dundee (Scotland): 191-200.

4. Goffinet C (2009) Influence of the reuse of OSB and marine plywood formworks on concrete facing color. Master Thesis, Faculté des Sciences Appliquées, Université de Liège (Belgium), 105p (in French).

5. Migeotte N (2009) Influence of the reuse of OSB and marine plywood formworks on concrete facing texture. Master Thesis, Faculté des Sciences Appliquées, Université de Liège (Belgium), 119p (in French).

6. Dieryck V, Desmyter J, Michel F and Courard L (2005) Surface quality of SelfCompacting Concrete and Raw Materials Properties. In: Second North American Conference on the Design and Use of Self-Consolidating Concrete (SCC) and the Fourth International RILEM Symposium on Self-Compacting Concrete, (Ed. S. P. Shah, Center for Advanced Cement-Based Materials, McCormick School of Engineering and Applied Science, Northwestern University, Evanston, IL 60208, U.S.A.), Published by Hanley Wood, Addison, IL 60101, USA: 287-295.

7. Lallemant I, Rougeau P, Gallias J L and Cabrillac R (2000) Contribution of microscopy to the characterization of concrete surfaces presenting local tint defects. $22^{\text {nd }}$ International Conference on Cement Microscopy, Montréal, April $29^{\text {th }}$-May $4^{\text {th }}: 107-121$.

8. Kreijger P C (1984) The skin of concrete: composition and properties. Mater Struct 17(100): 275-283.

9. Lemaire G, Escadeillas G and Ringot E (2005) Evaluating concrete surfaces using an image analysis process. Constr Bldg Mat 19: 604-611.

10. Thompson MS (1969) Blowholes in concrete surfaces. Concrete: 64-66.

11. Lallemant I (2001) Heterogeneity of tint on concrete surface: characterization and mechanisms identification. PhD thesis, Université de Cergy-Pontoise (France), 285p (in French).

12. Martin M (2007) Study of the texture of vertical formworked concrete surfaces. PhD Thesis, Université Laval (Quebec, Canada) and Université de Cergy-Pontoise (France) : 225p (in French).

13. Martin M, Gilson A and Courard L (2008) Aesthetic evaluation and control of concrete building surfaces. Materials and Sensations 2008, Pau (France), Oct. 22-24.

14. Gilson A and Courard L (2007) Attempt to objectify the aesthetic characteristics of concrete siding. In: Conférence «Le béton apparent: un défi d'excellence », IFSB, Luxembourg (in French).

15. Apers J et al (2006) Concrete technology. Belgian Concrete Association, Brussels : 605p.

16. Martin M, Goffinet C, Migeotte N, Michel F et Courard L (2009) Le béton apparent : influence de l'état de surface du moule sur l'aspect des surfaces. Journées scientifiques du Regroupement Francophone pour la Recherche et la Formation dans le domaine du béton, Paris (France): 36-50.

17. Baty G and Reynolds R (1997) Release agents - how they work. Conc Int 19(10): 52-54.

18. Lallemant I, Rougeau P, Gallias J L and Cabrillac R (2000) Study of local tint defects on concrete surface: influence of superplasticizers and other parameters. Proceedings of the 
$6^{\text {th }}$ Canmet/ACI Symposium on Superplasticizers and other admixtures, Nice (France): 521-534.

19. Perez F, Bissonnette B and Courard L (2009) Combination of mechanical and optical profilometry techniques for concrete surface roughness characterization. Mag Concr Res 61(6): 389-400.

20. Courard L, Michel F and Martin M (2011) The evaluation of the surface free energy of liquids and solids in concrete technology. Constr Bldg Mat 25: 260-266.

21. Courard L and Degeimbre R (2003) A capillary suction test for a better knowledge of adhesion process in repair technology. Can. J. Civil Eng., 30(6): 1101-1110.

22. NBN B15-215: 1969 (Belgian standard) Tests on concrete: water absorption by immersion. 